\title{
CONDUCTIVITY NEAR THE METAL-TO-INSULATOR TRANSITION IN $\mathrm{Cd}_{1-x} \mathrm{Mn}_{x} \mathrm{Se}_{\mathrm{Sc}}{ }^{*}$
}

\author{
P. Glód, M. Sawicki, A. Lenard, T. Dietl and W. Plesiewicz \\ Institute of Physics, Polish Academy of Sciences, Al. Lotników 32/46, 02-668 \\ Warszawa, Poland \\ (Received August 8, 1990)
}

\begin{abstract}
Earlier studies of transition metal impurities in II-VI compounds suggest that $\mathrm{Sc}$ acts as a resonant donor. We performed Hall effect and conductivity measurements of CdSe:Sc and $\mathrm{Cd}_{0.95} \mathrm{Mn}_{0.05} \mathrm{Se}: \mathrm{Sc}$. The results, particularly the critical concentration of the metal-to-insulator transition, turned out to be similar to those obtained previously for $\mathrm{Cd}_{1-x} \mathrm{Mn}_{x}$ Se doped with hydrogenic-like impurities, such as In and $\mathrm{Ga}$. Therefore, if the ground state of Sc impurity is indeed located above the bottom of the conduction band, our data demonstrate that the metal-to-insulator transition is primarily driven by the scattering, i.e. it corresponds to the Anderson localization.
\end{abstract}

PACS numbers: $71.30 .+h, 71.55 . J v$

It is generally accepted that the formation of local states by impurities with open magnetic shells cannot be described within the one-electron effective mass approximation [1]. For instance, $\mathrm{Mn}$ in CdSe gives rise to a donor state which lies about $3 \mathrm{eV}$ below the top of the valence band, while the $\mathrm{Sc}$ donor level is expected to be degenerate with the conduction band [2]. If indeed the lowest donor state of $\mathrm{Sc}$ is located above the bottom of the conduction band, $\mathrm{Cd}_{1-x} \mathrm{Mn}_{x} \mathrm{Se}: \mathrm{Sc}$ offers a rather unique opportunity to shed new light on the nature of electron localization in doped semiconductors. This is because the metal-to-insulator transition may be driven by two distinct mechanisms [3]:

(i) quantum localization of the Fermi liquid induced by scattering (Anderson localization);

*This work was supported by the Institute for Low Temperature and Structural Research, Polish Academy of Sciences. 
(ii) conversion of the Fermi-liquid quasiparticles into local electron magnetic moments (Mott-Hubbard transition).

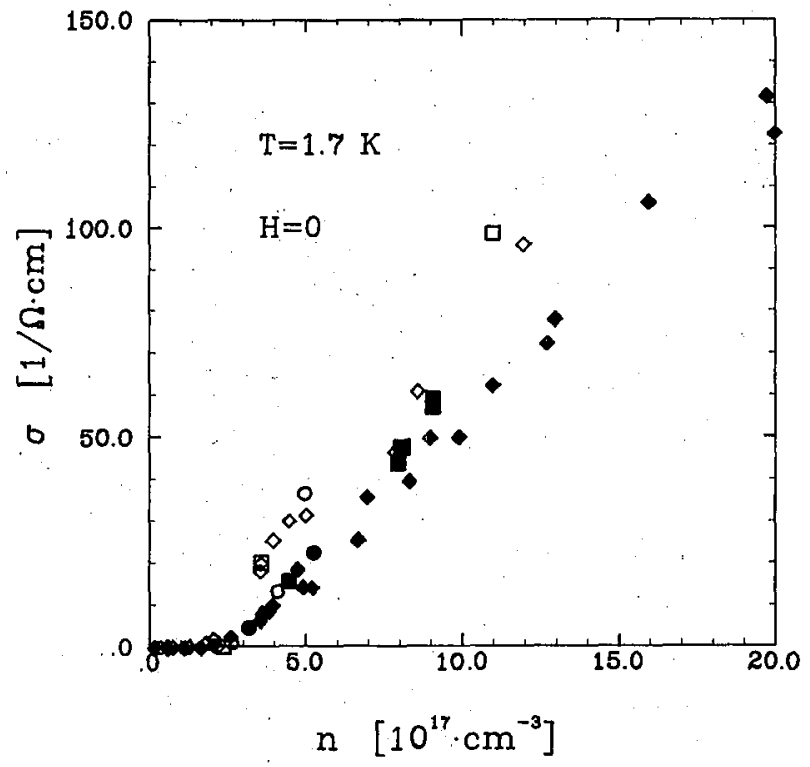

Fig.1. Conductivity as a function of electron concentration for $n$-CdSe and $n$-Cd $\mathrm{Cd}_{0.95} \mathrm{Mn}_{0.05} \mathrm{Se}$ (open and solid symbols, respectively): squares CdSe:Sc, Cd0.95 Mno.05 Se:Sc (this work); rhombs - CdSe:In, Cd0.95 Mn $\mathrm{Mn}_{0.05} \mathrm{Se}: \mathrm{In}$ [4-6]; circles - CdSe [7]; $\mathrm{Cd}_{0.95} \mathrm{Mn}_{0.05} \mathrm{Se}: \mathrm{Ga}$ [8].

In the case when the potential of a single impurity has no bound states (as is probably the case of $\mathrm{Sc}$ in $\mathrm{CdSe}$ ), the localization by the Mott-Hubbard mechanism should be inoperative. At the same time Anderson's metal-to-insulator transition may occur as a result of the collective action of many scattering centers on the electron motion.

The CdSe:Sc and $\mathrm{Cd}_{0.95} \mathrm{Mn}_{0.05} \mathrm{Se}: \mathrm{Sc}$ crystals were grown by the Bridgman method, with the concentration of $S c$ ranging from $5 \times 10^{17} \mathrm{~cm}^{-3}$ to $10^{18} \mathrm{~cm}^{-3}$. The electrical contacts to the Hall-bar samples were prepared by soldering indium in helium atmosphere. The measurements were performed using either a.c. or d.c. techniques.

The conductivity of our samples at $T=1.7 \mathrm{~K}$ as a function of electron concentration deduced from Hall effect data at $300 \mathrm{~K}$ is shown in Fig. 1 in comparison with previous results for $\mathrm{CdSe}$ and $\mathrm{Cd}_{0.95} \mathrm{Mn}_{0.05}$ Se doped with hydrogenic-like donors. We see, that $\mathrm{Sc}$ doping produces electrons and therefore Sc acts indeed as a donor whose energy level is either resonant with the conduction band or very shallow. Furthermore, the conductivity of $\mathrm{Cd}_{1-x} \mathrm{Mn}_{x} \mathrm{Se}: \mathrm{Sc}$ and, in particular, the critical concentration of the metal-to-insulator transition are similar to those of 
$\mathrm{Cd}_{1-x} \mathrm{Mn}_{x}$ Se containing hydrogenic-like dopants. Also, no significant difference between $\mathrm{Cd}_{1-x} \mathrm{Mn}_{x} \mathrm{Se}: \mathrm{Sc}$ and $\mathrm{Cd}_{1-x} \mathrm{Mn}_{x}$ Se:In was noted when studying the magnetoresistance and the temperature dependence of conductivity, as shown in Fig. 2.

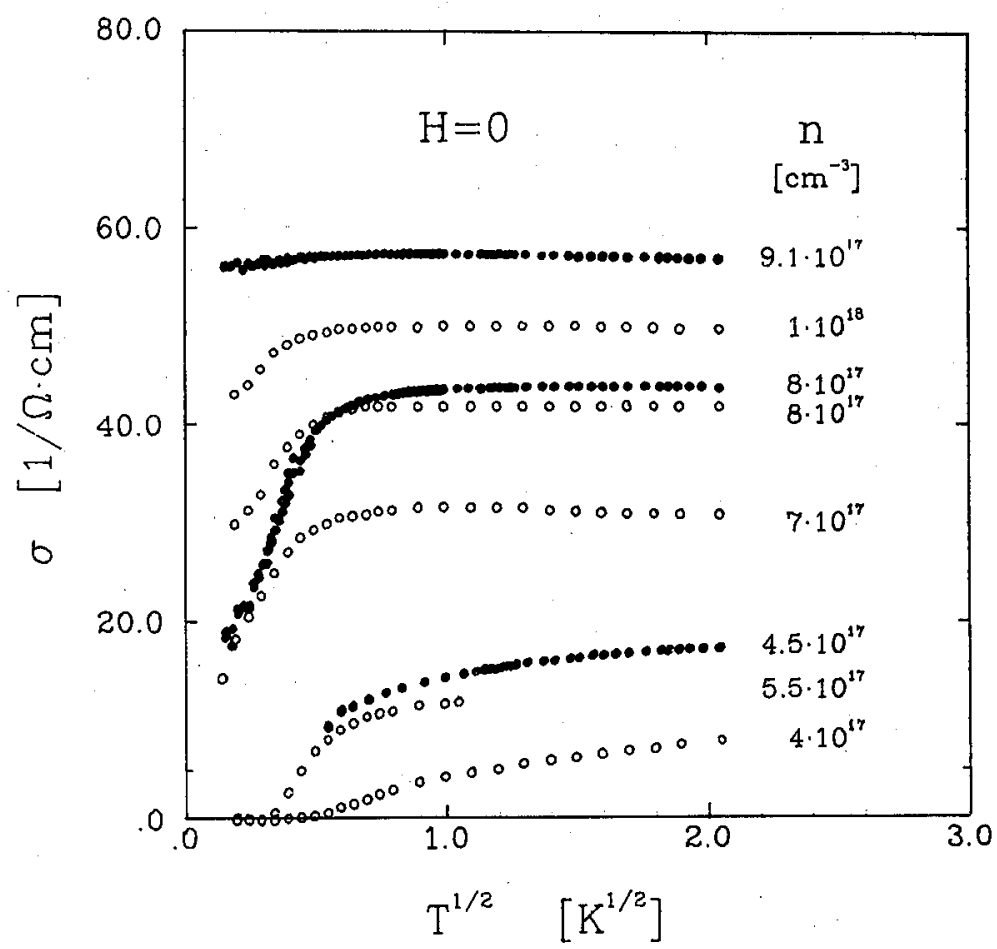

Fig. 2. Conductivity as a function of temperature for $n$ - $\mathrm{Cd}_{0.95} \mathrm{Mn}_{0.05}$ Se: solid symbols $-\mathrm{Cd}_{0.95} \mathrm{Mn}_{0.05} \mathrm{Se}: \mathrm{Sc}$ (this work); open symbols $-\mathrm{Cd}_{0.95} \mathrm{Mn}_{0.05} \mathrm{Se:In}$ [6].

Our results provide therefore a new indication that localization in doped semiconductors is caused primarily by the Anderson mechanism. Further work is in progress to substantiate this conclusion and, in particular, to find out whether $\mathrm{Sc}$ creates only the resonant states, as well as to elucidate the role of native defects and impurities in $\mathrm{Cd}_{1-x} \mathrm{Mn}_{x} \mathrm{Se}: \mathrm{Sc}$.

\section{References}

[1] see, e.g., P. Vogl, J.M. Baranowski, Acta Phys. Pol. A67, 133 (1985);

A. Zunger, in Solid State Physics, Vol 39, eds. F. Seitz, D. Turnbull, Academic Press, New York 1986, p. 275;

V.I. Sokolov, Fiz. Tverd. Tela 29, 1848 (1987);

Sov. Phys.- Solid State 29, 1061 (1987); 
J.M. Langer, C. Delerue, M. Lannoo, H. Heinrich, Phys. Rev. B 38, 7723 (1988).

[2] J.M. Baranowski, J.M. Langer, Phys. Status Solidi B 48, 863 (1971).

[3] see, e.g. Anderson Localization, eds. T. Ando, H. Fukuyama, Springer, Berlin 1988;

Electron-Electron Interactions in Disordered Systems, eds. A.L. Efros, M. Pollak, North-Holland, Amsterdam 1985;

T. Dietl, Acta Phys. Pol. A73, 793 (1988).

[4] M. Sawicki, T. Dietl, J. Kossut, J. Igalson, T. Wojtowicz, W. Plesiewicz, Phys. Rev. Lett. 56, 508 (1986).

[5] T. Dietl, L. Świerkowski, J. Jaroszyński, M. Sawicki, T. Wojtowicz, Phys. Scr. T14, 29 (1986).

[6] T. Dietl, M. Sawicki, T. Wojtowicz, J. Jaroszyński, W. Plesiewicz, L. Świerkowski, J. Kossut, in Anderson Localizalion, eds. T. Ando, H. Fukuyama, Springer, Berlin 1988, p. 58.

[7] D.M. Finlayson, J. Irvine, L.S. Peterkin, Philos. Mag. B 39, 253 (1979).

[8] Y. Shapira, N.F. Oliveira, D.H. Ridgley, R. Kershaw, K. Dwight, A. Wold, Phys. Rev. B 34, 4187 (1986) 